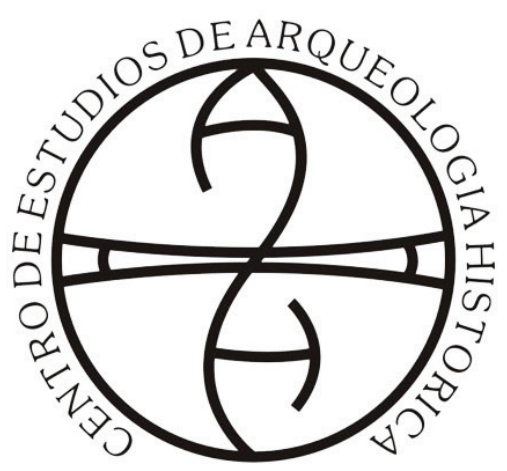

Centro de Estudios de Arqueología Histórica

Universidad Nacional de Rosario

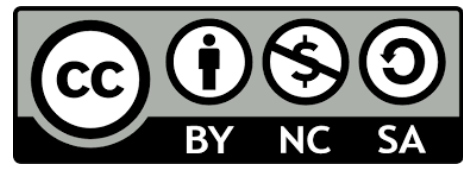

Teoría y Práctica de la Arqueología Histórica

Latinoamericana | Especial: Documentos de Trabajo |

Año II, Número 2 | 2021

Revista del Centro de Estudios de Arqueología Histórica, Facultad de Humanidades y Artes, Universidad Nacional de Rosario

https://teoriaypracticaah.unr.edu.ar/index.php/index

https://rephip.unr.edu.ar/handle/2133/14804

ISSN en línea: 2591-2801

ISSN versión impresa: 2250-866X

Atribución-NoComercial-CompartirIgual 4.0 Internacional (CC BY-NC-SA 4.0)

https://creativecommons.org/licenses/by-nc-sa/4.0/deed.es

Martha C. Hernández (ID.: https://orcid.org/0000-00031751-158X) y Diógenes Patiño Castaño (ID.: https://orcid. org/0000-0002-0110-0017). Arqueología histórica de una urbe colonial, Popayán, Colombia

\title{
ArQueOlogía histórica de UNA URBE COLONIAL, Popayán, Colombia
}

\author{
Martha C. Hernández * y Diógenes Patiño Castaño **
}

\section{Resumen}

Este artículo se refiere a los trabajos en arqueología histórica llevados a cabo en la urbe colonial de Popayán, ciudad que tuvo enorme importancia en la historia de Colombia. Su transformación y expansión ha expuesto las materialidades culturales del pasado, que, interpretadas, nos hablan de sus gentes y dinámicas socioculturales en esta región desde la Colonia.

Palabras clave: Arqueología Histórica, Colonia, Popayán, Colombia

\begin{abstract}
This article deals to the work in historical archeology carried out in the colonial city of Popayán, a city that had enormous importance in the history of Colombia. Its transformation and expansion have exposed the cultural materials of the past, which, interpreted, tell us about its people and sociocultural dynamics in this region since the colonial times.

Keywords: Historical Archeology, Colonia, Popayán, Colombia

* Arqueóloga independiente. Universidad del Cauca. Centro de Estudios de Arqueología Histórica (CEAH) - Instituto Dr. Adolfo Prieto, Facultad de Humanidades y Artes, Universidad Nacional de Rosario. https://orcid.org/0000-0003-1751-158X. marthaseh@hotmail.com.

** Profesor Departamento de Antropología. Universidad del Cauca. Centro de Estudios de Arqueología Histórica (CEAH) Instituto Dr. Adolfo Prieto, Facultad de Humanidades y Artes, Universidad Nacional de Rosario.

https://orcid.org/0000-0002-0110-0017. diopatin@unicauca.edu.co.
\end{abstract}


Teoría y Práctica de la Arqueología Histórica Latinoamericana | Especial: Documentos de Trabajo

Año II, Número 2 | 2021 / ISSN en línea: 2591-2801 | ISSN versión impresa: 2250-866X

\section{Introducción}

Los estudios recientes de arqueología histórica en la urbe colonial de Popayán se han desarrollado a partir de las intervenciones del modernismo contemporáneo, que ha venido transformando el sector histórico de la ciudad y sus alrededores. Estudios arqueológicos preventivos del patrimonio cultural local, han develado a través de la materialidad cultural diversas actividades sociales, económicas y políticas que marcaron la ciudad y sus habitantes desde épocas coloniales. Los diferentes hallazgos en sitios arqueológicos coloniales y republicanos han sido estudiados en diferentes contextos culturales, donde se perciben dinámicas y relaciones sociales y de consumo en estas épocas históricas. La materialidad recuperada en cada rincón de la urbe colonial marcada por su historicidad permite cotejar el dato arqueológico con el dato histórico para reescribir las historias no contadas de grupos étnicos de la Popayán antigua y clasista. La ciudad fue uno de los centros más importantes de la colonia española en Suramérica. En este sentido las teorías y métodos de la Arqueología Histórica son herramientas importantes para la interpretación de las sociedades de nuestra pasado reciente.

\section{Arqueología histórica, teoría y método}

Los estudios en Arqueología Histórica son relevantes por cuanto relacionan culturas y grupos sociales con la multivocalidad. Esta área de la antropología, arqueología e historia se encuentra íntimamente relacionada con aspectos de recurrente actualidad como son la reconstrucción cultural y la memoria ancestral de los pueblos desde un pasado histórico, arqueológico y antropológico (Funari y Zarankin, 2004; Patiño y Zarankin, 2010; Schávelzon, 2001). En cierta forma la Arqueología Histórica contradice los estudios tradicionalistas de la historia, en especial aquellas de los relatos nacionalistas, que estuvieron encaminados al análisis estadísticos y economicistas de diferentes épocas, olvidando a sus propios actores en su diario vivir y formas de pensar. Contrario a esto, varios autores han trabajado estos temas desde una arqueología crítica social con enfoques desde la multivocalidad histórica, surgiendo, así, nuevos relatos sobre la historia, memoria y tradiciones de los grupos sociales olvidados. La Arqueología Histórica combina en sus métodos el uso de las fuentes históricas documentales (archivos), datos arqueológicos y narrativas; en los primeros, la investigación usa documentos escritos, en la segunda, estudios de la materialidad arqueológica en contextos culturales y, la última, el uso de la oralidad tradicional en grupos de descendientes. Para alcanzar sus logros la Arqueología Histórica se fundamenta en la interdisciplinaridad para interpretar y conceptualizar sobre los grupos sociales subalternos y su cultura, enfatizando sobre las problemáticas sociales, económicas y políticas centradas en los inicios del capitalismo en América y el mundo moderno. También la arqueología como herramienta de la memoria y la identidad debe sumarse a propósitos que contribuyan a la validez de los derechos de los grupos étnicos sociales, de tal manera que respondan a los desafíos de la construcción y definición de las sociedades como entidades políticas actuales (Hall y Silliman, 2006; Hicks y Beaudry, 2006; Orser, 2004, 1996; Patiño, 2020; Williams, 1994).

\section{Arqueología Histórica en la Urbe Popayán Colonial}

En Colombia, en las últimas décadas, se vienen desarrollando con cierto interés estudios en arqueología histórica de las épocas de la Colonia, Independencia y la República. Los sitios más destacados han sido aquellos históricos como: Cartagena de Indias, Mompox, Santa Fe, Cali, Neiva y Popayán, entre otros. En la reconstrucción y conservación de las ciudades la Arqueología Histórica juega un rol prepon- 
Teoría y Práctica de la Arqueología Histórica Latinoamericana | Especial: Documentos de Trabajo Año II, Número 2 | 2021 / ISSN en línea: 2591-2801 | ISSN versión impresa: 2250-866X

derante, que permite conservar y rescatar elementos de la cultura material que nos ayudan a entender aquellos contextos sociales y culturales de nuestro pasado más reciente. Por otro lado, se contribuye a la conservación y protección de los lugares de memoria urbana con sitios arqueológicos y monumentales que son vistos como patrimonios culturales de gran valor para nuestras futuras generaciones.

Popayán y su gobernación fue una de las regiones coloniales más importante del Nuevo Reino de Granada. La provincia y la ciudad durante los siglos XVI hasta mediados del XIX fue gobernada por familias españolas y criollas, quienes sometieron como mano de obra a las comunidades indígenas locales bajo la institución de la encomienda y a grupos de esclavos negros traídos del occidente de África, para las explotaciones de las minas de oro y las haciendas agrícolas y ganaderas coloniales. G. Colmenares (1979) acertó en llamar a la urbe "ciudad de esclavistas" ya que se convirtió en un centro de distribución de negros y negras africanos.

En la época colonial en términos generales, las manzanas o cuadras cercanas a la plaza central contenían las propiedades de los gobernantes españoles, personas que se desempeñaban como administradores, militares o clérigos; más alejados de estos círculos sociales y espacios culturales se hallaba la clase de comerciantes y los grupos menos favorecidos ocupaban zonas periféricas y desarrollaban actividades en varios oficios (artesanos, arrieros, agricultores, joyeros, etc.). Los grupos sociales más pobres se ubicaron en el sur y occidente de la urbe, sus casas en ladrillo y bahareque ocupaban lotes medianos con huertas y animales domésticos; no poseían elementos suntuarios o de elaborada arquitectura (Patiño, 2020). Los esclavos trabajaban para sus amos y eran importantes por su valor en la economía comercial (hasta 500 patacones) usados en el servicio de las casonas de la urbe, haciendas y minas. La llegada de esclavos se dinamiza en la región debido a la caída demográfica de la población indígena, por las enfermedades y la explotación sin límites de las encomiendas de españoles.

En el siglo XVII ya se veían mezclas raciales entre blancos, indios y negros, sus descendiente se los distinguía por el color de la piel, formando una población mestiza, hoy reconocida como pluriétnica y multicultural (Pérez, 2018; Díaz, 1994).

Con los estudios en Arqueología Histórica de Popayán se han llevado a cabo excavaciones en varias localidades que incluyen calles del sector histórico, edificios y casonas las cuales fueron ocupadas desde épocas coloniales. Algunos de ellos son conservados como bienes de interés cultural patrimonial y turístico en el sector histórico (e.g., iglesias, conventos, casonas).

\section{Materialidades en la ciudad. Sitios y excavaciones}

Los trabajos de Arqueología Histórica en Popayán han arrojado evidencias de diferentes momentos de desarrollo de la ciudad y de sus habitantes. Redes de acueductos y alcantarillados del siglo XVIII y XIX, cajas de distribución y cajas desarenadoras de aguas limpias para el servicio de la ciudad (Hernández, 2018) han sido reportadas y registradas con abundantes contenidos de materiales arqueológicos asociados (Figura 1, Fotos 1, 2, 3 y 4).

El primer acueducto de la ciudad fue construido en 1712 por don Jacinto de Mosquera y don Francisco José Arboleda, quienes trajeron desde Poblazón las aguas conducidas por gravedad usando acequias y tubos en barro para el servicio de las Monjas del monasterio de La Encarnación y para las casas de las familias mencionadas en el centro de la ciudad; de allí seguían las acequias hasta la plaza central, atravesando la calle de La Compañía (Carrera 8 y Calle 5).

En 1764-1766 Pedro Agustín Valencia, tesorero de la Casa Real de La Moneda proporcionó el agua a las casonas de familias prestantes, edificios de gobierno y conventos a través de canaletas en ladrillo por

Arqueología histórica de una urbe colonial, Popayán, Colombia

M. C. Hernández y D. Patiño Castaño

Páginas 9-23 
donde conducía el agua traída de los cerros orientales de Popayán. Este sistema fue ampliándose a toda la ciudad hasta ser necesario que el Cabildo nombrara una junta de notables para conservar las redes y administrar el servicio, generando así un cobro de $\$ 5$ pesos la paja de agua $\left(2 \mathrm{~cm}^{3}\right.$ por segundo). Esto se regulaba mediante cajas distribuidoras ubicadas en las esquinas de las calles (Actas de Cabildo de 179295; Colonia sig. 8708).
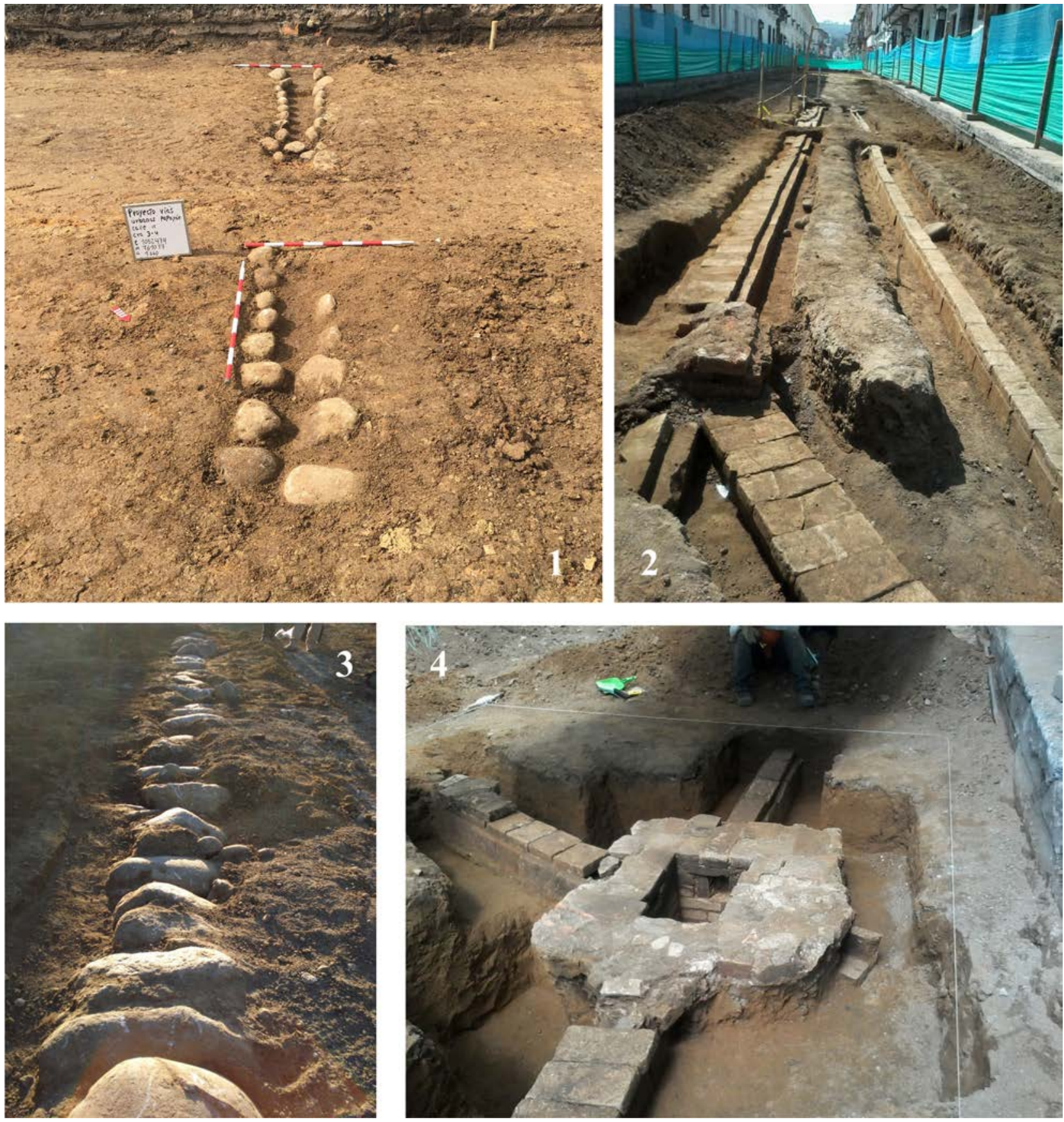

Figura 1. Foto 1. Acequia para conducir aguas limpias. Fotos 2, 3 y 4 . Sistemas de acueducto en ladrillo y piedra para aguas limpias (Fotos de 2015 y 2019, autoría M. Hernández y D. Ordoñez). 
Teoría y Práctica de la Arqueología Histórica Latinoamericana | Especial: Documentos de Trabajo Año II, Número 2 | 2021 / ISSN en línea: 2591-2801 | ISSN versión impresa: 2250-866X

En el siglo XIX se continúa la ampliación de las redes de acueductos y alcantarillados necesarios para la ciudad, estas funcionaron hasta principios del siglo XX, cuando la infraestructura antigua de las redes cambia y son reemplazadas por tubos y canales en cemento y metal (Hernández, 2018; Archivo Histórico Departamental, 1962).

Otras estructuras de ingeniería colonial, que se refieren al pasado y la importancia vital del agua, son las Pilas o chorros privados y públicos, sobre estos últimos se asume que eran lugares de gran contenido social, ya que debieron ser espacios donde se dieron diversas relaciones interculturales siendo un sitio de gran valor social para los habitantes de la ciudad.

Los trabajos arqueológicos actuales han reportado y recuperado hasta el momento un chorro de uso público y dos chorros de uso privado; de estos últimos existen otros mencionados por estudios anteriores en la ciudad (Méndez, 2007; 2011). Con relación al chorro público este se localizó en la calle de San Camilo (Carrera 8 con Calle 10), son de forma semilunar y de tamaño reducido $\left(1.5 \mathrm{~m}^{2}\right.$ ); (Figura 2, Foto 5) mientras que los privados de forma rectangular; uno reconstruido y el otro en proceso de restauración fueron hallados en casonas de familias pudientes del siglo XVIII y XIX (Fotos 6 y 7). Estos chorros son comunes en estos espacios y se reportan también en las instituciones administrativas, conventos religiosos y en las haciendas coloniales de propiedad de la elite o familias pudientes, quienes poseían sus propios chorros y aljibes privados con construcciones bien elaboradas en piedra de cantera y ladrillo (Foto 8). Igualmente, estos elementos suntuarios y de aseo representan una marcada diferencia entre lo privado y lo público en las sociedades coloniales de la Nueva Granada.

Documentos del archivos histórico mencionan que desde 1802 se trató de adelantar la obra esperada de las fuentes públicas y en 1828 se proyectó la construcción de fuentes o chorros públicos para la clase trabajadora y artesanal que vivía en el sector de San Camilo y El Empedrado, quienes habían solicitado al gobierno una fuente para obtener el agua gratuita, puesto que no tenían los medios suficientes para pagar por el servicio (Archivo Central del Cauca, ACC, Fondo Cabildo 1828, Tomo 65, folio 23r-v).

En el año de 1871 el jefe municipal hizo establecer cuatro fuentes para uso público, distribuidas de la siguiente manera: una en el barrio de San Francisco, otra en la esquina de la Ermita, otra en San Agustín y la cuarta en San Camilo. Se pedía que el gasto total de las obras pagadas por el tesoro del Municipio no excediera de 50 pesos, los cuales se tomarían de la suma apropiada para obras públicas (ACC, Fondo Cabildo 1871 Tomo 85, Folio 52r). Estos chorros construidos en varias calles de Popayán fueron de vital importancia, no solo por la obtención del agua, sino además como se mencionó, por la interacción social en estos lugares comunales, donde debieron tejerse historias de la vida cotidiana y social, compartiendo memorias y saberes que marcaron el devenir histórico y cultural de la sociedad.

La cotidianidad de los siglos XVIII y XIX está siendo interpretada a través de los contenidos arqueológicos asociados a estas estructuras, además de patios, espacios públicos y áreas de servicio doméstico donde la materialidad es abundante y compleja. Existen estratos de rellenos profundos con basuras de distintas épocas, donde abundan materiales variados siendo los más comunes las cerámicas locales y foráneas. 

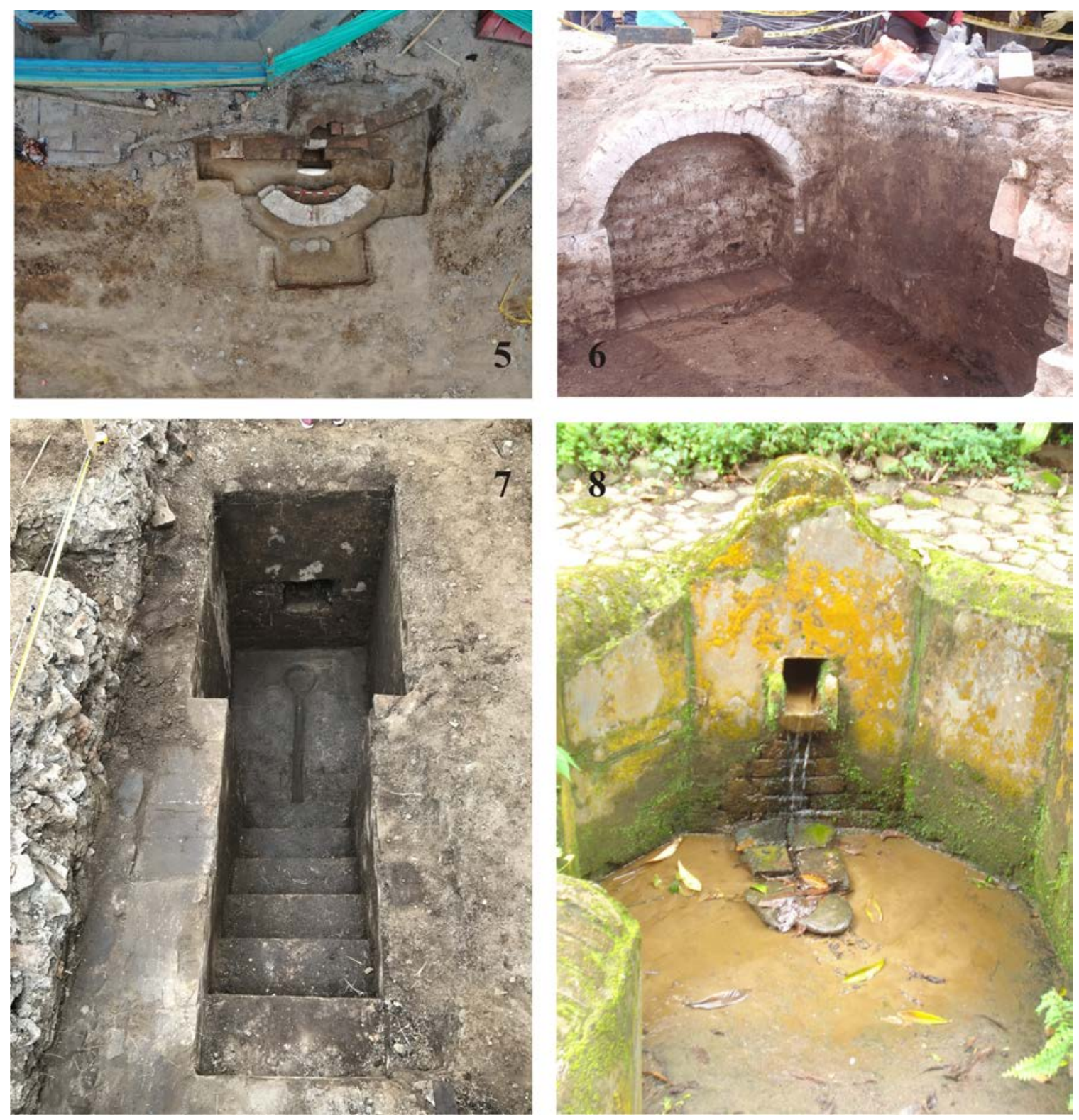

Figura 2. Foto 5. Chorro Público en San Camilo. Chorros privados: Foto 6, Casa Sánchez. Foto 7, Casa Humanidades y Foto 8, Hacienda Yambitará. Fotos de M. Hernández del año 2018.

Cerámicas de producción local, producción foránea, novohispanas y europeas, porcelanas, lozas y vidrios presenta una variedad que formaron parte del menaje doméstico de la época y que cumplieron un propósito en la sociedad que los consumió en la preparación de sus alimentos, en el servicio de estos en la mesa, para luego terminar como productos que sirven a la interpretación histórica en la arqueología (Figura 3). 

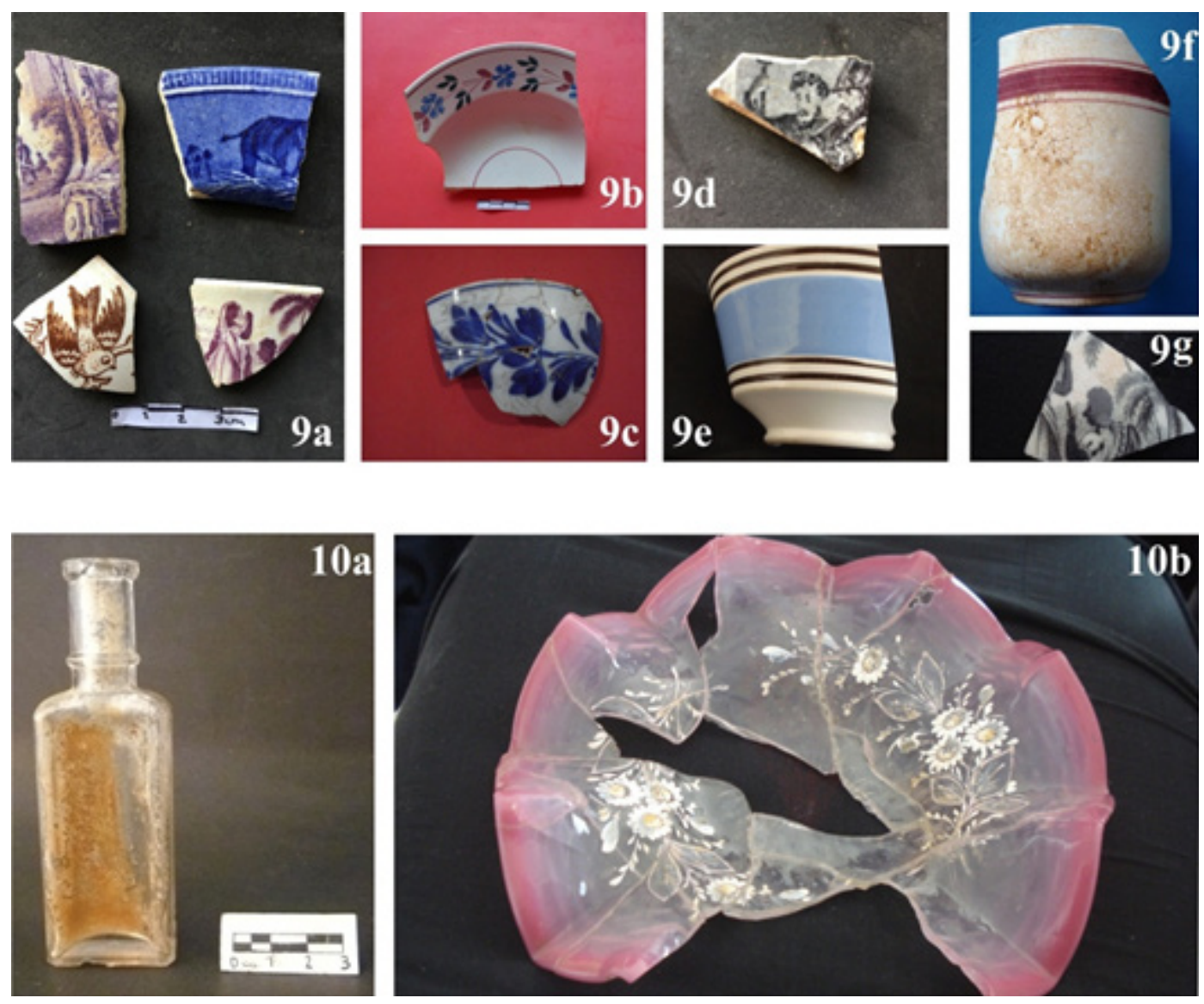

Figura 3. Lozas europeas: 9a, 9d y 9g, impresión por transferencia. 9b, Floreal pintada a mano. 9c, Floreal pintada a mano azul sobre blanco. 9e, anular bandeada. 9f, lineal pintada a mano. Curaduría Hernández 2018. Fotos $10^{\mathrm{a}}$ y 10b. Vidrios siglo XIX. Curaduría de M. Hernández del año 2018.

En la urbe los materiales culturales arqueológicos más recurrentes son las alfarerías locales e importadas. Los sitios donde se perciben abundantes desperdicios corresponden a las áreas de servicios y patios en edificios institucionales y casonas. Allí es notorio la mezcla de cerámicas de tradición europea con la cerámica de producción local, conocida como criolla, indígena y africana. Elementos técnicos alfareros de estas tres fuentes han sido reconocidos en los conjuntos cerámicos analizados en estos espacios habitacionales de la ciudad.

En trabajos anteriores en Popayán (Caicedo, 2006; Méndez, 2007; Londoño 2011) es recurrente encontrar referencias de esta producción alfarera en la colonia y épocas posteriores, así como importantes productos importados de otras latitudes de América y Europa; especialmente, lozas, mayólicas, porcelanas, botellas de vidrio y otras mercancías necesarias para la vida de las familias en la ciudad. Estos materiales culturales y sus usos también diferenciaban claramente los grupos sociales de la urbe, las clases sociales eran celosamente determinadas e iban desde una élite payanesa hasta la subalternidad de las gentes del común. Los materiales culturales afro atestiguan la presencia de esclavos, libres africanos y sus descendientes en la ciudad y otros espacios coloniales. Está documentado que la importación de esclavos negros africanos, traídos por Cartagena de Indias, Honda o a través de Buenaventura (costa 
Pacífica), trajeron consigo ideas y técnicas propias de sus culturas y etnias africanas. El traslado de estos conocimientos tuvieron una reconfiguración y recontextualización en América bajo el sistema esclavista colonial (Patiño, 2020).

Estos materiales europeos se han encontrado con mayor frecuencia en ciertos lugares de la ciudad, permitiendo detectar zonas residenciales donde la evidencia de elementos coloniales fue más fuerte que en otras. Para el centro de la ciudad la materialidad está compuesta por objetos de elevado valor en el mercado como mayólicas traídas de diferentes sitios de producción como España, Francia, Portugal, Italia, cerámicas Novohispanas producidas en América, México, Panamá y Perú, entre otros enclaves españoles en el Nuevo Mundo (Figura 4, Fotos 11 y 12). Las porcelanas Ming, Imarí, Ching y Kraak (Deagan, 1987) son frecuentes en los sectores de monasterios y casonas (Figura 4, Foto 13); algunas son locales y otras de producción europea que quisieron imitar la calidad asiática de las porcelanas.
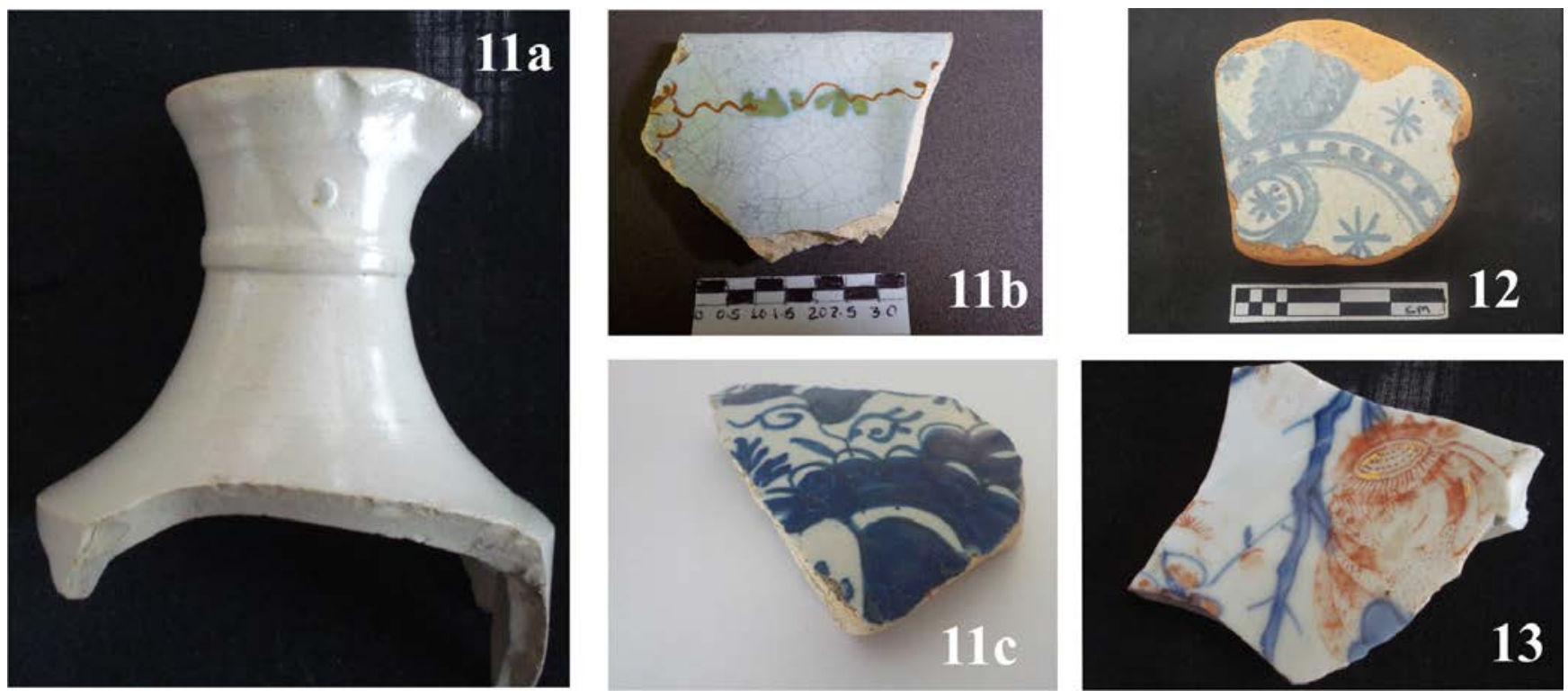

Figura 4. Foto 11 a, b y c. Mayólicas europeas. Foto 12. Novohispana americana. Foto 13 Porcelanas Imari. Curaduría de M. Hernández del año 2019.

Por otro lado, también son frecuentes las cerámicas de producción local con influencia española (Figura 5) es decir manufacturadas con torno y con uso de la técnica del vidriado a partir del óxido de plomo, elemento que introdujo cambios en la preparación de los alimentos y su servicio en las mesas coloniales; mayor vistosidad (estilos). Estos materiales estuvieron en todos los ámbitos sociales, aunque en menor frecuencia las cerámicas que imitaron las mayólicas europeas producidas en Popayán tardíamente, además de demandar costos por la obtención del estaño que era importado. Este menaje fue más de uso culinario que de servicio, por lo menos, para la alta sociedad que prefería una mesa suntuosa con objetos traídos de afuera. 


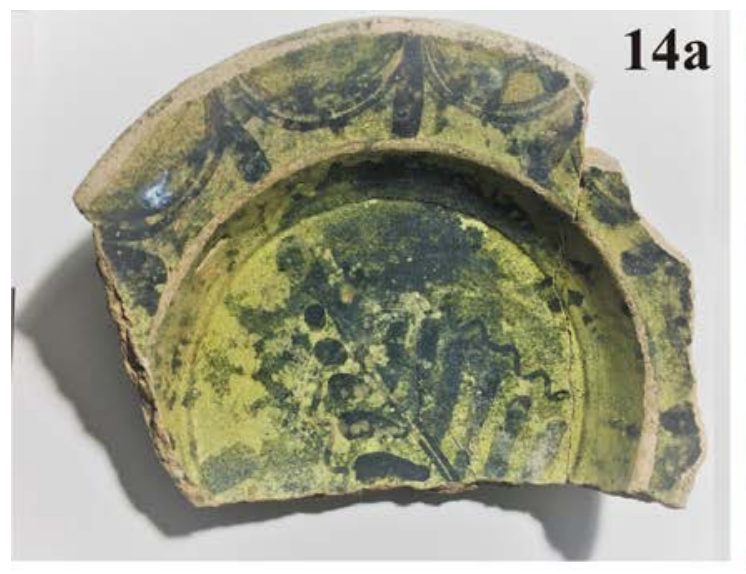

CALLE 10 ENTRE CARRERA 7 Y 8

Formas varas del reliono 5
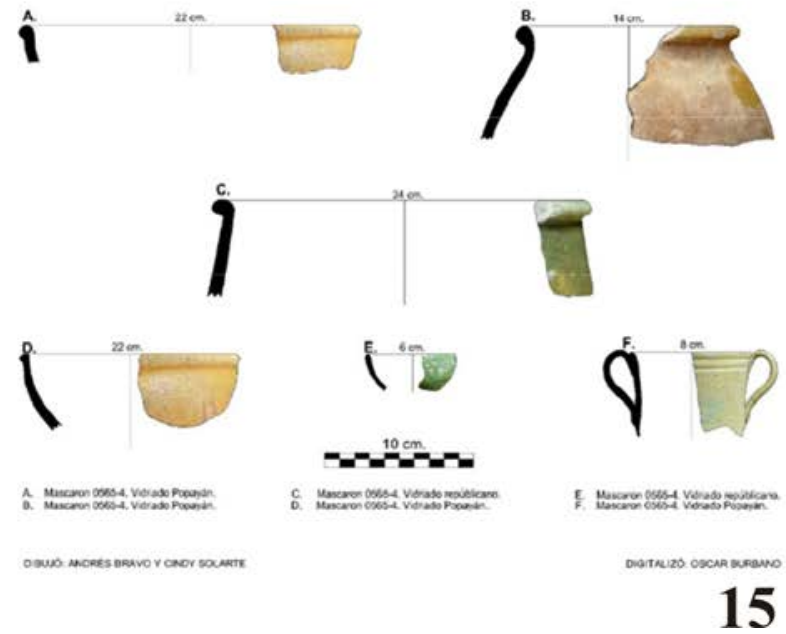

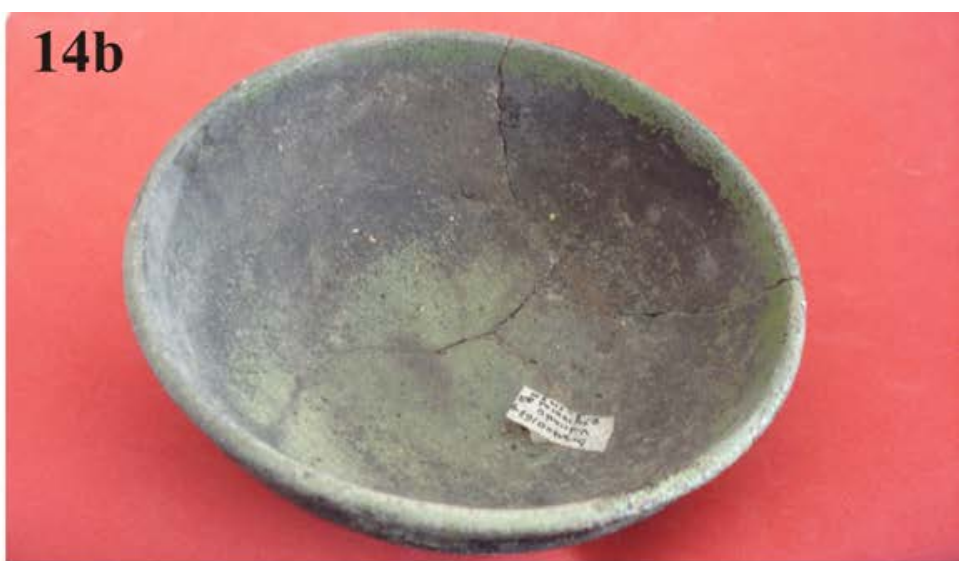

CARERRA A RELLENO G
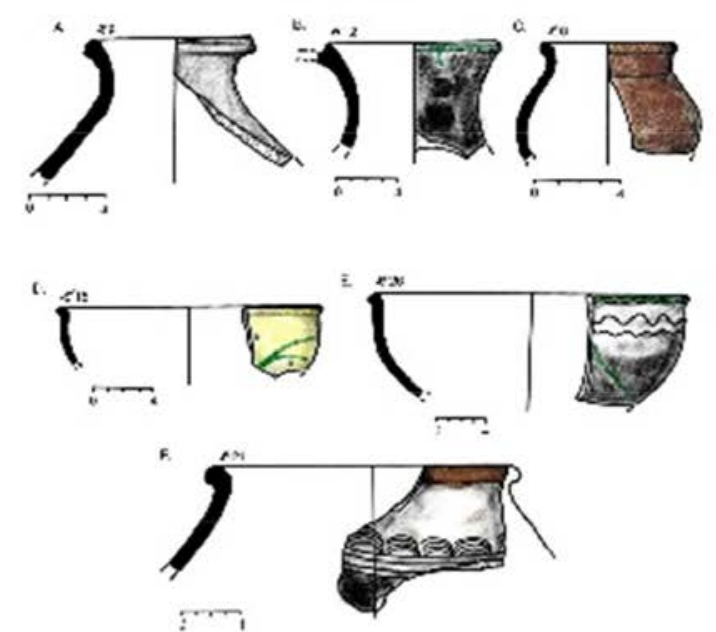

16

Figura 5. Foto 14a y b, Cerámicas locales. Curaduría de M. Hernández del año 2017. Fotos 15 y 16. Reconstrucción formas cerámicas producción local. Dibujo de Andrés Bravo y Cindi Solarte. Digitalización Oscar Burbano 
Las cerámicas de tradición indígena (Figura 6) continuaron produciéndose artesanalmente hasta mucho después de la colonia con una variedad de formas y características que permite inferir un sincretismo cultural, entre los grupos sociales que coexistieron, observándose en cierta medida resistencia en el uso de técnicas alfareras manteniendo sus tradiciones frente al uso exclusivo de elementos de afuera.
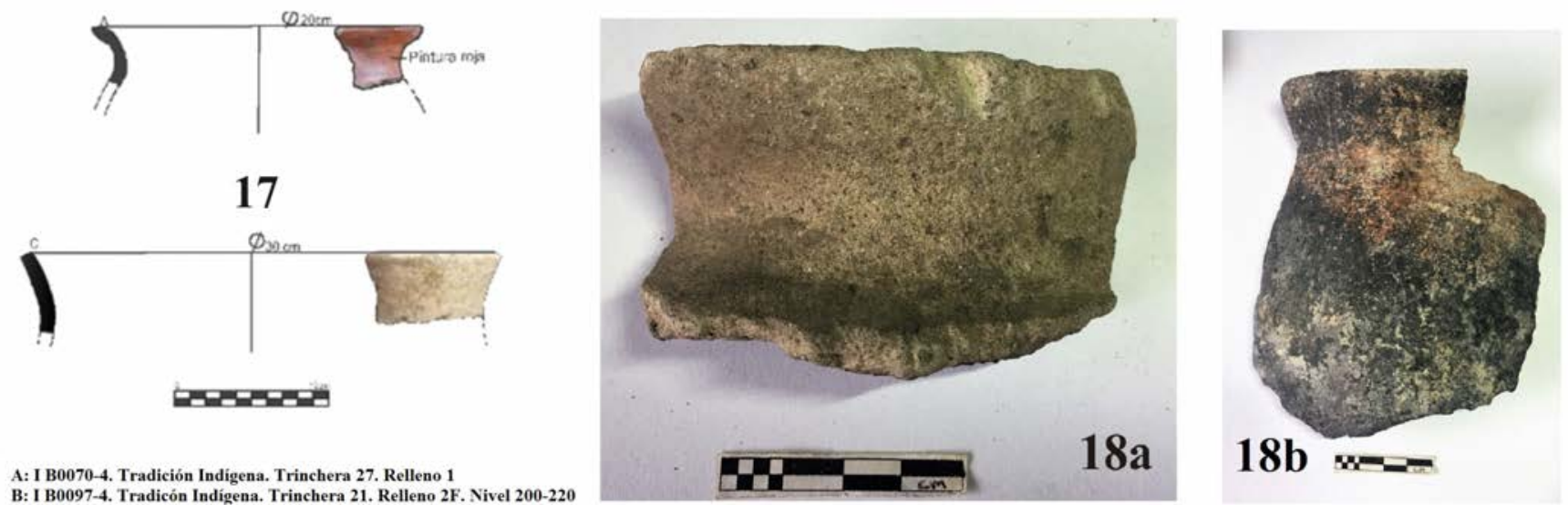

Figura 6. Foto 17: Formas cerámicas tradición indígena. Foto $18 \mathrm{a}$ y 18b: cerámicas de tradición indígena. Curaduría de M. Hernández del año 2016.

Desgrasantes más finos, formas cerámicas compartidas, uso de tecnologías ancestrales y mayor control de la temperatura, caracterizan este tipo de alfarería, frecuente en todos los ámbitos de la ciudad mostrando permanencia a través de su manufactura (Figura 6, Fotos 17 y 18).

Otro grupo de cerámicas diferentes a las de tradición indígena y criolla, se caracteriza por una manufactura netamente modelada y superficies ennegrecidas derivadas de la función de las vasijas en los fogones; sus diseños son el esgrafiado, presión digital en los bordes de vasijas globulares, impresión e incisión de líneas cortas que simulan la escarificación de cuerpos y presencia de símbolos como la X que representa el cosmograma Bakongo de la religiosidad africana (Bantú-Muntú). Además, es común la presencia de pipas en cerámica decoradas con incisiones y líneas curvas (Fotos 19 y 20). Estos materiales se los asocia con la presencia de grupos de esclavos africanos en los diferentes sitios y espacios estudiados en la ciudad (Patiño, 2020). 


\section{Relleno 6}

Ceramica de Influencia Afro.
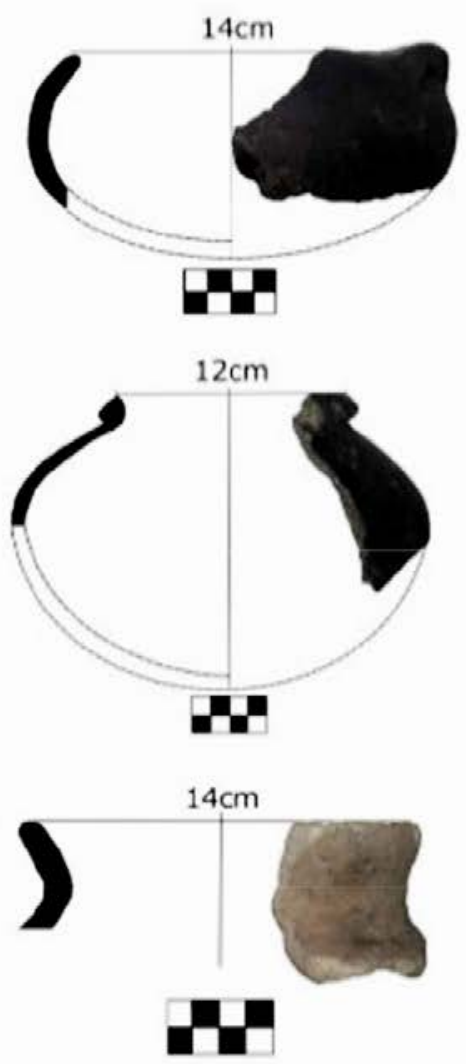
A. Influencia Afro. Relleno 6. Cma 0499-4
B. Influencia Afro. Relleno 6. Cma 0499-4
C. Influencia Afro. Relleno 6. Cma 0499-4
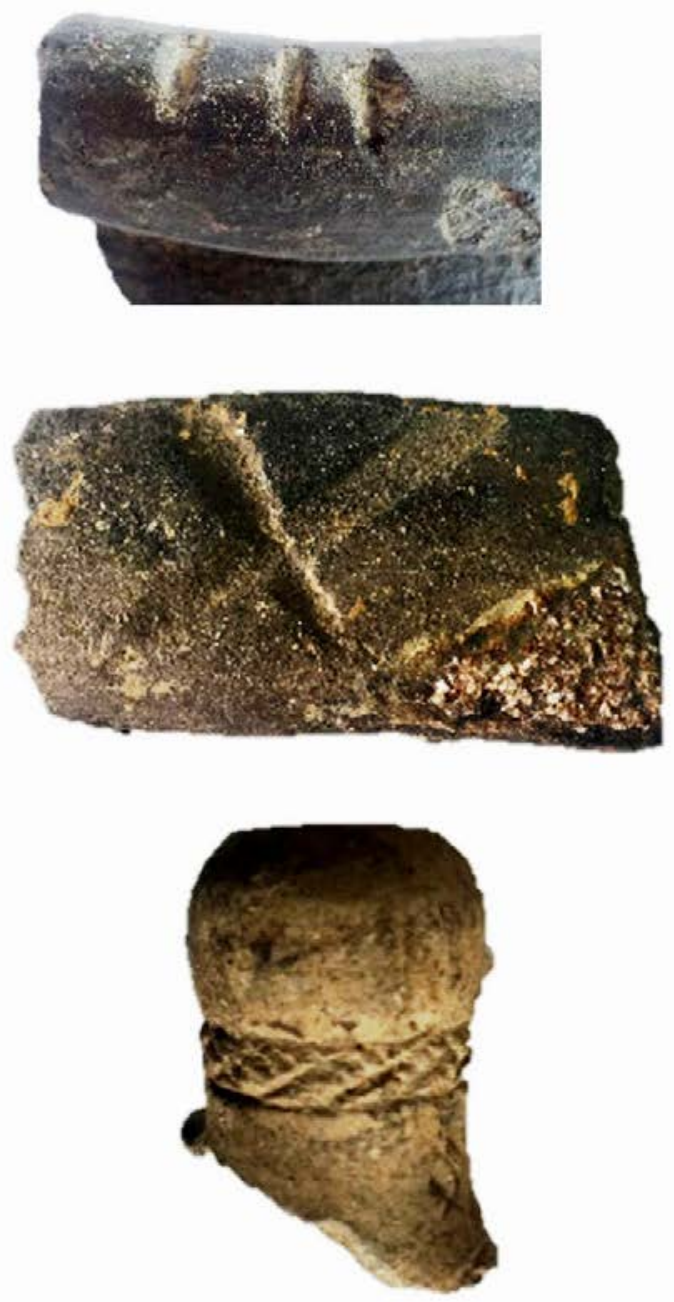

Figura 7. Foto 19. Formas cerámicas Afro. Foto 20. Cerámicas Afro.

Curaduría de M. Hernández del año 2018.

En la Tabla 1 y Tabla 2 se aprecian las frecuencias de los pesos en gramos (gr.) de los materiales alfareros coloniales hallados en el sector del centro de la ciudad como en su periferia. Estos dos espacios se definen en términos generales por la disposición de la ciudad que fue construida en forma de damero desde su fundación, el centro se caracteriza por las cuadras, aproximadamente unas 30, cercanas a la plaza central donde se instaló la aristocracia colonial con instituciones, edificios y casonas. El área de la periferia se caracterizaba por unas 35 cuadras, dispuestas sobre todo al sur de la ciudad, donde se conformaron barrios de comerciantes, maestros de obra, artesanos y herreros todos de población criolla y mestiza (Pérez, 2018). 
Teoría y Práctica de la Arqueología Histórica Latinoamericana | Especial: Documentos de Trabajo

Año II, Número 2 | 2021 / ISSN en línea: 2591-2801 | ISSN versión impresa: 2250-866X

Tabla 1. Frecuencia de peso en gramos (gr.) y porcentaje de materiales culturales en la ciudad de Popayán.

\begin{tabular}{|c|c|c|c|}
\hline $\begin{array}{c}\text { AREAS URBE / } \\
\text { TRADICIONES ALFARERAS }\end{array}$ & $\begin{array}{l}\text { CENTRO } \\
(\mathrm{gr} / \%)\end{array}$ & $\begin{array}{l}\text { PERIFERIA } \\
(\mathrm{gr} / \%)\end{array}$ & TOTAL $(\%)$ \\
\hline \multirow{2}{*}{ MAYÓLICAS EUROPEAS } & 95032 & 4005 & \\
\hline & $12 \%$ & $3.3 \%$ & \\
\hline \multirow{2}{*}{ NOVOHISPANAS } & 4458 & 85 & \\
\hline & $1 \%$ & $0,1 \%$ & \\
\hline \multirow{2}{*}{$\begin{array}{l}\text { CERAMICAS LOCALES CON } \\
\text { INFLUENCIA EUROPEA }\end{array}$} & 298045 & 55970 & \\
\hline & $38 \%$ & $46 \%$ & \\
\hline \multirow{2}{*}{ LOZA } & 25949 & 3757 & \\
\hline & $3.3 \%$ & $3.1 \%$ & \\
\hline \multirow{2}{*}{ PORCELANA } & 5363 & 548 & \\
\hline & $0.7 \%$ & $0.4 \%$ & \\
\hline \multirow{2}{*}{$\begin{array}{l}\text { CERAMICA TRADICIÓN } \\
\text { INDÍGENA }\end{array}$} & 330171 & 47155 & \\
\hline & $42 \%$ & $39 \%$ & \\
\hline \multirow{2}{*}{$\begin{array}{c}\text { CERAMICA INFLUENCIA } \\
\text { AFRO }\end{array}$} & 20600 & 1786 & \\
\hline & $3 \%$ & $1.5 \%$ & \\
\hline \multirow{2}{*}{ CERAMICAS INDÍGENAS } & 0 & 9018 & \\
\hline & $0 \%$ & $7 \%$ & \\
\hline \multirow{2}{*}{ TOTAL (gr/\%) } & 779618 & 122324 & 901942 \\
\hline & $100 \%$ & $100 \%$ & $100 \%$ \\
\hline
\end{tabular}

La muestra proviene de los trabajos arqueológicos que se vienen adelantando en la ciudad. M. Hernández 2018-2019. 
Tabla 2. Distribución porcentual de alfarerías en Popayán. Elaboración propia.

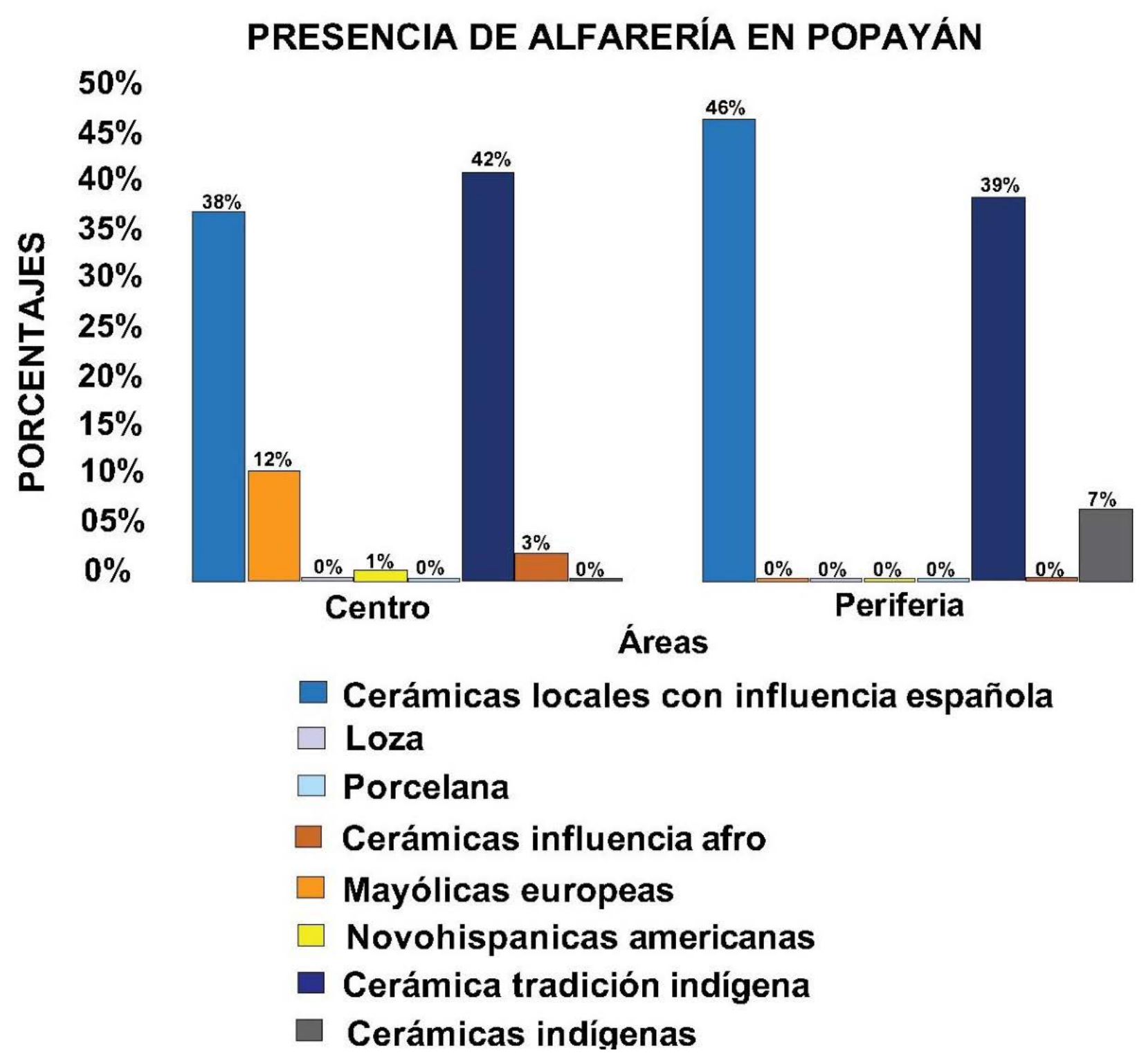

Las cerámicas de tradición indígena reportadas en la arqueología de la ciudad se presentan en todos sus ámbitos siendo de uso común en la mayoría de los sectores sociales lo que la hace popular y de alto consumo en las cocinas a partir del siglo XVIII hasta la república. Luego tenemos las cerámicas de producción local con influencia europea, donde se hace especial el uso del torno. Mientras que las cerámicas de producción europea y novohispanas son frecuentes en el centro de la ciudad y muy escasas en la periferia lo que permite confirmar su uso suntuoso (de gran valor comercial) y de prestigio por ciertos círculos sociales. 
Teoría y Práctica de la Arqueología Histórica Latinoamericana | Especial: Documentos de Trabajo Año II, Número 2 | 2021 / ISSN en línea: 2591-2801 | ISSN versión impresa: 2250-866X

Las cerámicas de influencia afro se observan preferiblemente en el sector histórico de la ciudad donde la presencia del esclavo está documentada claramente en los archivos históricos mostrando al esclavo más como un objeto de producción y de prestigio para las familias españolas y criollas con un estatus social quienes tenían haciendas y casonas atendidas por esclavizados.

\section{Conclusiones}

La Arqueología Histórica ha sido una herramienta de investigación que ha dado pasos hacia el análisis de nuevos contextos sociales en nuestros territorios nacionales, especialmente en el tratamiento de los nuevos contextos sociales y culturales para épocas diversas de la historia reciente latinoamericana. En el caso de Popayán, una urbe colonial española, nuevas aplicaciones de la Arqueología Histórica muestran en el tratamiento de las materialidades excavadas en diversos espacios socioculturales aspectos de la vida cotidiana en la ciudad.

En términos generales la arquitectura de los chorros y piletas van acorde con las edificaciones e indican relaciones sociales antagónicas en épocas coloniales; los espacios ocupados por las élites de poder se caracterizan por ocupar el centro de la urbe, mientras que grupos subalternos se repliegan a barrios populares y áreas de servicios, haciéndose notorio una fuerte división de las clases sociales.

Estos aspectos también se reflejan en los materiales culturales alfareros con producciones locales de consumo popular y aquellas importadas que se asocian al poder adquisitivo y riquezas de las familias élites de la ciudad colonial. A futuro se prevé continuar estudios en Arqueología Histórica en la ciudad con el fin de profundizar en estos temas en el área urbana como en la rural y conocer más sobre aquellas relaciones socioculturales y de la vida cotidiana entre los grupos de poder y las subalternidades en el mundo colonial hispano del sur de Colombia.

Por último, este estudio aún se lleva a cabo en la urbe, sus resultados finales se darán a conocer en el futuro después de realizar el muestreo total en la ciudad.

\section{Referencias bibliográficas}

Caicedo, A. S. 2006. Arqueología del contacto cultural en la Popayán colonial: finales del siglo XVI y siglo XVII. Tesis de grado. Departamento de Antropología. Universidad del Cauca. Popayán.

Colmenares, G. 1979. Historia económica y social de Colombia II: Popayán, una sociedad esclavista 1600-1800. Bogotá: La Carreta.

Deagan, K. (1987). Catálogo de la Florida, USA. Recuperado de: https://www.floridamuseum.ufl.edu/ histarch/coleccion-digital-de-tipologias/. Último Acceso 24/01/2020.

Díaz, Z. (1994). Oro, Sociedad y Economía. El Sistema Colonial en la Gobernación de Popayán: 15331733. Bogotá: Banco de la República.

Funari, P. y Zarankin, A. 2004. Arqueología histórica en América del Sur. Bogotá: Universidad de los Andes.

Hall, M. y Silliman, S. 2006. Historical Archaeology. Malden: Blackwell Publishing. 
Teoría y Práctica de la Arqueología Histórica Latinoamericana | Especial: Documentos de Trabajo Año II, Número 2 | 2021 / ISSN en línea: 2591-2801 | ISSN versión impresa: 2250-866X

Hernández, M. C. (2015). Monitoreo arqueológico en la red de acueducto y alcantarillado. Sistema estratégico de transporte público en la ciudad de Popayán. (En prensa).

Hernández, M. C. (2018). Excavaciones y monitoreo arqueológico en el lote Bicentenario. Casa Sánchez. Popayán: Universidad del Cauca. Icanh. (En prensa).

Hicks, D. y Beaudry, M. (2006). The Cambridge Companion to Historical Archaeology. Cambridge: Cambridge University Press.

Londoño, W. 2011. Arqueología histórica de Popayán y la visibilización de su cultura tradicional. En: Revista Colombiana de Antropología 47(1): 91-112

Méndez, M. (2007). Historia y arqueología de la unidad conventual de San Francisco de Popayán. Popayán: Diseño Gráfico e Impresiones.

Méndez, M. (2011). Pilas, Chorros y Aljibes de Popayán. Popayán: Editorial López.

Orser, C. (1996). Images of the Recent Past: Readings in Historical Archaeology. London: Altamira Press.

Orser, C. (2004). Historical Archaeology. New Jersey: Pearson Prentice Hall.

Patiño, D. (2020). Arqueología e historia de la diáspora africana en el Cauca, Colombia. Popayán: Editorial Universidad del Cauca.

Patiño, D. y Zarankin, A. 2010. Arqueologías históricas. Patrimonios diversos. Popayán: Universidad del Cauca.

Pérez, M. T. 2018. Hábitat, Familia y Comunidad en Popayán 1750-1850. Popayán: Editorial Universidad del Cauca.

Schávelzon, D. 2001. Catálogo de cerámicas históricas de Buenos Aires (Siglos XVI-XX). Buenos Aires: FADU. http://www.iaa.fadu.uba.ar/cau/?p=1110. Último acceso: 8/02/2020.

Williams, E. 1994. Capitalism and Slavery. Chapel Hill and London: University of North Caroline Press.

\section{Repositorios Consultados}

Archivo Central del Cauca, Popayán. Universidad del Cauca.

Gobernación del Cauca. 2020. Archivo histórico Departamental. Popayán. 